\title{
Stress-associated hormone, norepinephrine, increases proliferation and IL-6 levels of human pancreatic duct epithelial cells and can be inhibited by the dietary agent, sulforaphane
}

\author{
CHRISTINA CHAN ${ }^{1}$, HUEY-JEN LIN ${ }^{2,3}$ and JIAYUH LIN ${ }^{1,3,4}$ \\ ${ }^{1}$ Center for Childhood Cancer, Columbus Children's Research Institute and Department of Pediatrics, College of Medicine, \\ ${ }^{2}$ Medical Technology Division, School of Allied Medical Professions, ${ }^{3}$ The Ohio State University \\ Comprehensive Cancer Center, The Ohio State University, Columbus, OH 43205, USA
}

Received February 29, 2008; Accepted April 18, 2008

DOI: 10.3892/ijo_00000023

\begin{abstract}
In current literature there is evidence that psychological factors can affect the incidence and progression of some cancers. Data obtained from animal models support the hypothesis that stress can be a cofactor. The underlying mechanisms for the association between psychological factors and pancreatic cancer are very poorly understood. In this study, we examined the possible growth promoting effects of the stress-associated hormone, norepinephrine, on immortalized human pancreatic duct epithelial cells. Our results suggest that norepinephrine can increase cell proliferation of human pancreatic duct epithelial cells. We also evaluated the ability of norepinephrine to induce interleukin-6 (IL-6), interleukin-10 (IL-10), and vascular endothelial growth factor (VEGF). All of which may promote oncogenesis of immortalized human pancreatic duct epithelial cells. We found that norepinephrine can increase the IL-6 and VEGF but not IL-10 levels secreted by human pancreatic duct epithelial cells. Since norepinephrine can increase cell proliferation of human pancreatic duct epithelial cells, we performed further testing to see if dietary agents, sulforaphane and resveratrol, can inhibit norepinephrine-mediated increases in cell proliferation in human pancreatic duct epithelial cells. Interestingly, our results demonstrated that sulforaphane but not resveratrol inhibits norepinephrine-mediated increases in cell viability in human pancreatic duct epithelial cells. Furthermore, sulforaphane also inhibits norepinephrine-mediated increase of the IL-6 levels but not VEGF levels. Our study is the first to demonstrate that stress-associated hormone, norepinephrine,
\end{abstract}

Correspondence to: Dr Jiayuh Lin, WA5020, Center for Childhood Cancer, Department of Pediatrics, The Ohio State University, 700 Children's Drive, Columbus, OH 43205, USA

E-mail:1in.674@osu.edu

Key words: norepinephrine, IL-6, sulforaphane can increase the cell proliferation and IL-6 levels of human pancreatic duct epithelial cells, which can be inhibited by sulforaphane, a chemopreventive agent and a natural compound from the Cruciferous vegetables.

\section{Introduction}

Pancreatic cancer is one of the most serious types of cancers. Each year approximately 32,000 individuals in the United States are diagnosed with pancreatic cancer. The American Cancer Society estimates that for the year 2007 there will be 37,170 new cases and 33,370 deaths from pancreatic cancer in the United States alone. Cancer of the exocrine pancreas is rarely curable and has an overall survival rate of $<4 \%$ (1). The highest cure rate occurs if the tumor is truly localized to the pancreas; however, this stage of the disease accounts for $<20 \%$ of cases. For those patients with localized disease and small cancers $(<2 \mathrm{~cm})$ with no lymph node metastases and no extension beyond the capsule of the pancreas, complete surgical resection can yield actuarial 5-year survival rates of $18-24 \%$ (2). For patients with advanced cancers, the overall survival rate of all stages is $<1 \%$ at 5 years with most patients dying within 1 year $(3,4)$. There is evidence that psychological factors can affect the incidence and progression of some cancers $(5,6)$. Data obtained from animal models support the hypothesis that stress could be a cofactor $(7,8)$. Studies in the field of psychoneuroimmunology have shown that psychological stress can affect many aspects of cellular immune function through the modulation of the endocrine system. These interactions have been shown to be bidirectional $(9,10)$. Among cancer patients, behavioral factors may serve as predictors of clinical outcome, such as response to therapy and overall survival (11-15). These findings suggest that psychosocial stress factors not only affect the immune system adversely but also contribute to poor outcome in cancer patients.

Aside from stress-related changes in the immune response, recent studies suggest that stress can affect downstream events that may contribute to tumor progression such as angiogenesis and tumor metastasis (16-18). These processes involve 
matrix metalloproteinases (MMP) and the vascular endothelial growth factor (VEGF). VEGF has been well described as a cytokine important for endothelial cell proliferation and the process of angiogenesis essential for tumor development (19). MMP activity has been further linked to the complex process of tumor development (20). Recently, works by Sood et al $(17)$ and Lutgendorf et al $(16,18)$ have shown that the catecholamines, norepinephrine (NE) and epinephrine, may influence the progression of ovarian cancer by modulating the expression of MMPs and the angiogenic cytokine VEGF in ovarian cancer cells (21). The catecholamines, epinephrine and norepinephrine, are components of the sympathetic response that are propagated in the sympathetic nervous system and the adrenal medulla. Both norepinephrine and epinephrine are elevated in individuals with acute or chronic stress $(22,23)$. Studies in mice support these observations. Using social isolation stress, the mRNA levels of MMP-2, MMP-9 and others were higher in tumor and liver tissues of isolated mice than in control mice grouped together (24). To date, the association between psychological factors such as chronic stress and pancreatic cancer are very poorly understood. In this study, we examined the potential growth promoting effects of stress-associated hormone, norepinephrine, on human pancreatic duct epithelial cells. The objective of our study is to demonstrate that norepinephrine can increase the cell proliferation and IL-6 levels of human pancreatic duct epithelial cells and this induction can be inhibited by sulforaphane, a natural compound from the cruciferous vegetables.

\section{Materials and methods}

Human pancreatic duct epithelial cells. Immortalized human pancreatic duct epithelial cells were provided by Dr MingSound Tsao at the University of Toronto and were maintained in CnT-07CF epidermal keratinocyte medium (CELLnTEC Advanced Cell Systems, Bern, Switzerland) supplemented with $100 \mathrm{U} / \mathrm{ml}$ penicillin and $100 \mathrm{mg} / \mathrm{ml}$ streptomycin (Invitrogen Life Technologies, Carlsbad, CA) and $0.07 \mathrm{mM} \mathrm{CaCl}_{2}$ in addition to the manufacturer's provided supplements. These cells were cultured at $37^{\circ} \mathrm{C}$ and $5 \% \mathrm{CO}_{2}$.

MTT cell proliferation assay. Human pancreatic duct epithelial cells $\left(4 \times 10^{3}\right)$ were grown in $100 \mu 110 \%$ FBS-supplemented DMEM medium in 96-well flat-bottomed plates overnight. Cells were treated with norepinephrine $(5$ or $10 \mu \mathrm{M})$ that was dissolved in serum-free Dulbecco's modified Eagle's medium (DMEM) with or without 10 or $20 \mu \mathrm{M}$ of sulforaphane and resveratrol respectively (Sigma-Aldrich Co., St. Louis, MO) that was dissolved in Dimethyl Sulfoxide (DMSO) before being added to the medium. Cell viability was analyzed $72 \mathrm{~h}$ after the treatments by the MTT [3-(4, 5-dimethyl-2-thiazolyl)2, 5-diphenyl-2H-tetrazolium bromide] (Sigma-Aldrich) assay in three replicates and from two independent experiments. At the end-point, cells were treated with MTT $(1 \mathrm{mg} / \mathrm{ml})$ for 3-4 h. Colorimetric quantification was determined by an EL808 Ultra Micro-plate Reader (Bio-Tek Instruments, Inc., Winooski, VT) after the addition of formazan dissolved in $25 \% \mathrm{~N}, \mathrm{~N}$-dimethylformamide and $10 \%$ SDS under light-proof conditions overnight. Microsoft excel was used to analyze the cell viability data. The untreated cells were set at $100 \%$ and the cell viability of curcumin- and GO-Y030-treated cells was determined relatively to untreated cells. Results are presented as bar charts with error bars as needed. The statistical calculations will be performed using the SigmaStat statistical software package (SSSP, Chicago, IL).

ELISA assays. Human pancreatic duct epithelial cells were grown in 6-well dishes until they had reached $75-80 \%$ confluency. Their media werew then replaced with a $1: 1$ mixture of CnT-07CF and serum-free DMEM to a final volume of $3 \mathrm{ml}$ per well. These cells were then incubated for an additional $24 \mathrm{~h}$ prior to their respective treatments with 5 and $10 \mu \mathrm{M}$ of norepinephrine with or without 10 or $20 \mu \mathrm{M}$ of sulforaphane. The media were subsequently collected at the appropriate time-points, filter-sterilized, aliquoted and stored at $-80^{\circ} \mathrm{C}$. Secretion of IL-6 and VEGF (Peprotech, Rocky Hill, NJ) and IL-10 (Diaclone Co., Stamford, CT) was later quantified with ELISA kits per the manufacturer's instructions. Samples were assayed in duplicate. Error bars represent \pm standard deviation.

\section{Results}

Increased cell proliferation and viability of human pancreatic duct epithelial cells by norepinephrine is inhibited by the dietary agent, sulforaphane. We first examined whether norepinephrine could increase the cell proliferation of human pancreatic duct epithelial cells. Because there are no normal human pancreatic duct epithelial cells that are commercially available, we used immortalized human pancreatic duct epithelial cells which were provided by Dr Ming-Sound Tsao. Norepinephrine $(5$ and $10 \mu \mathrm{M})$ increases cell proliferation human pancreatic duct epithelial cells (Fig. 1A) to 2.5 -fold. We then explored if the dietary agents, sulforaphane and resveratrol, can inhibit the stimulation of cell proliferation of human pancreatic duct epithelial cells induced by norepinephrine. Our results showed that 10 and $20 \mu \mathrm{M}$ of sulforaphane have reduced cell proliferation of non-norepinephrine stimulated human pancreatic duct epithelial cells by $\sim 2$-fold (data not shown). Norepinephrine $(10 \mu \mathrm{M})$ increases cell proliferation of human pancreatic duct epithelial cells to $\sim 2.5$-fold compared to untreated human pancreatic duct epithelial cells (Fig. 1B). Interestingly, 10 and $20 \mu \mathrm{M}$ of sulforaphane reduced cell proliferation of norepinephrinestimulated human pancreatic duct epithelial cells by $\sim 5$-fold (Fig. 1B). In contrast, 10 and $20 \mu \mathrm{M}$ of another chemopreventive agent, resveratrol, did not inhibit cell proliferation of norepinephrine-stimulated human pancreatic duct epithelial cells (Fig. 1C). These results indicated that sulforaphane but not resveratrol has an inhibitory effect on norepinephrine stimulated cell proliferation in human pancreatic duct epithelial cells.

Norepinephrine increases the levels of IL-6 and VEGF in human pancreatic duct epithelial cells. It has been shown that norepinephrine can increase IL-6 and VEGF levels. We therefore examined whether norepinephrine can increase the levels of IL-6 and VEGF in human pancreatic duct epithelial cells. Our results showed that norepinephrine dramatically 
A

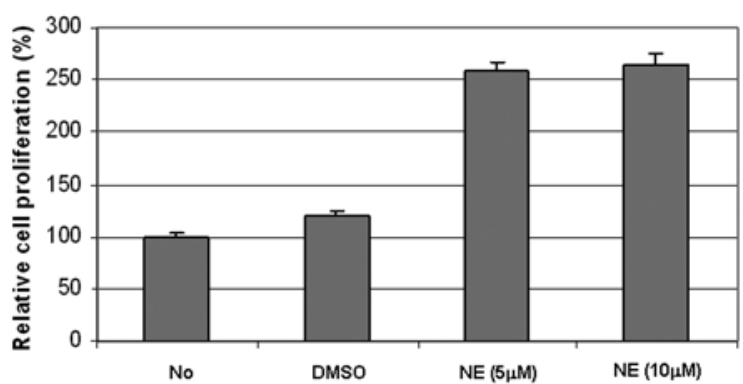

B

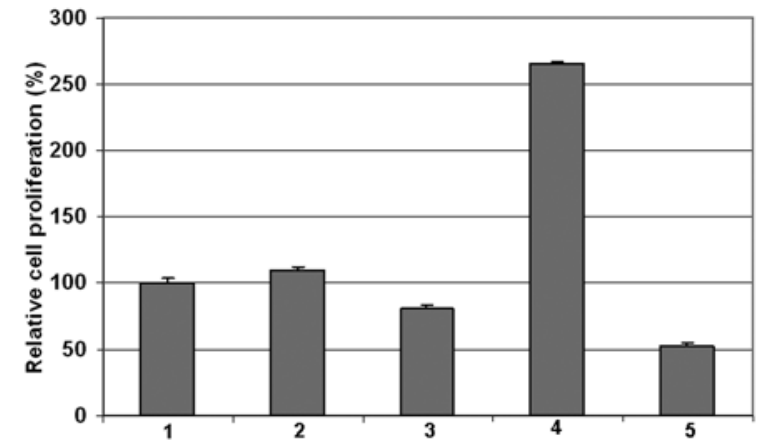

C

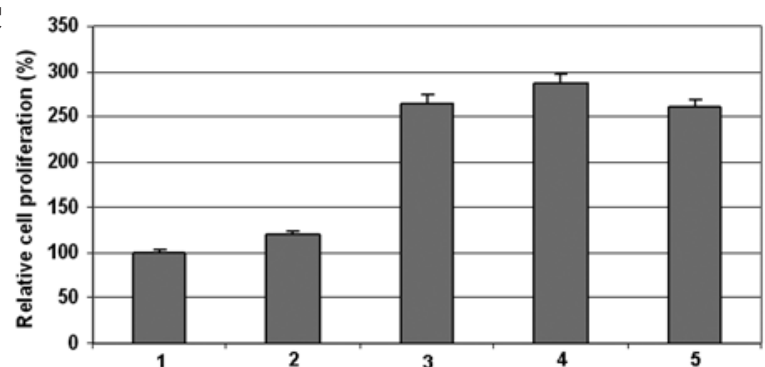

Figure 1. Norepinephrine (NE) increased the cell viability of human pancreatic duct epithelial cells and is inhibited by sulforaphane. (A) Human pancreatic duct epithelial cells were stimulated with 5 and $10 \mu \mathrm{M}$ of norepinephrine or Dimethyl Sulfoxide (DMSO) alone and MTT cell viability assays were determined at $72 \mathrm{~h}$ after the norepinephrine treatments. No, no treatment. (B) Human pancreatic duct epithelial cells with or without $10 \mu \mathrm{M}$ of norepinephrine stimulation were treated with or without 10 or $20 \mu \mathrm{M}$ of sulforaphane. 1, no treatment; 2, DMSO; 3 , sulforaphane $(10 \mu \mathrm{M}) ; 4$, NE $(10 \mu \mathrm{M}) ; 5$, NE $(10 \mu \mathrm{M})+$ sulforaphane $(10 \mu \mathrm{M})$. (C) Human pancreatic duct epithelial cells with or without $10 \mu \mathrm{M}$ of norepinephrine stimulation were treated with or without 10 or $20 \mu \mathrm{M}$ of resveratrol. 1, no treatment; 2, DMSO; 3 , NE $(10 \mu \mathrm{M}) ; 4, \mathrm{NE}(10 \mu \mathrm{M})+$ resveratrol $(10 \mu \mathrm{M}) ; 5, \mathrm{NE}(10 \mu \mathrm{M})+$ resveratrol $(20 \mu \mathrm{M})$. MTT cell viability assays were determined at $72 \mathrm{~h}$ after the norepinephrine treatments. The untreated cells $(0 \mu \mathrm{M})$ were set as $100 \%$ and the treated cells were determined relatively to untreated cells.

increases the levels of IL- 6 at 4 h post treatment and the IL- 6 levels continue to increase by $>80$-fold at $24 \mathrm{~h}$ post treatment in human pancreatic duct epithelial cells (Fig. 2A). In contrast, norepinephrine does not increase the levels of IL-10 during the 24-h treatment in HPDE cells (data not shown). Further, our results demonstrated that norepinephrine increases the levels of VEGF at $4 \mathrm{~h}$ post treatment and the VEGF levels continue to increase by more than 4 -fold at $24 \mathrm{~h}$ post treatment in human pancreatic duct epithelial cells (Fig. 2B).

Sulforaphane inhibits norepinephrine-mediated increases of IL-6 levels but not VEGF levels in human pancreatic duct epithelial cells. Since the chemopreventive agent, sulforaphane, has been shown to have inhibitory effects on norepinephrinemediated increases in cell proliferation of human pancreatic
A

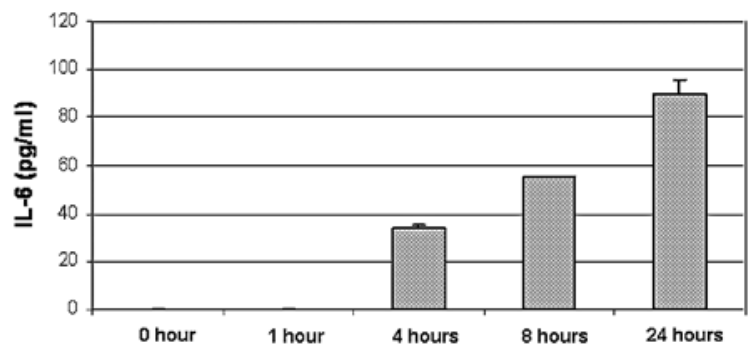

B

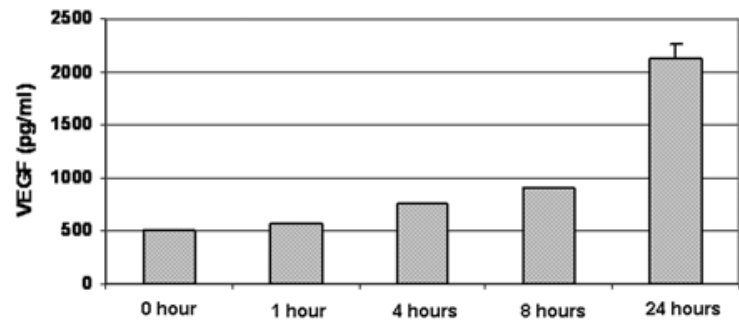

Figure 2. Norepinephrine increases the IL-6 and VEGF levels secreted in human pancreatic duct epithelial cells. (A) Human pancreatic duct epithelial cells were stimulated with $10 \mu \mathrm{M}$ of norepinephrine and IL-6 ELISA assays were determined at $0,1,4,8$, and $24 \mathrm{~h}$ after the norepinephrine treatments. (B) Human pancreatic duct epithelial cells were stimulated with $10 \mu \mathrm{M}$ of norepinephrine and VEGF ELISA assays were determined at $0,1,4,8$, and $24 \mathrm{~h}$ after the norepinephrine treatments.

\section{A}

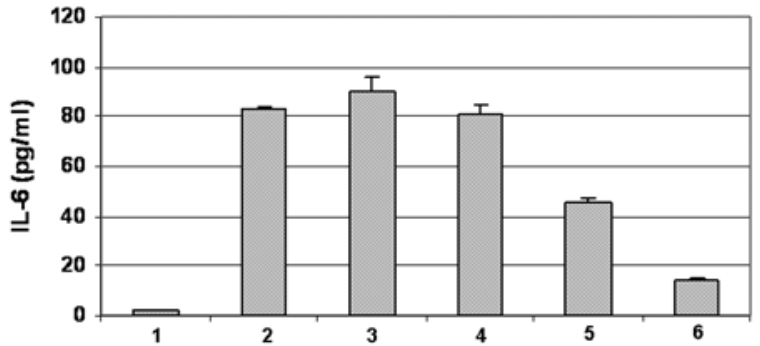

B

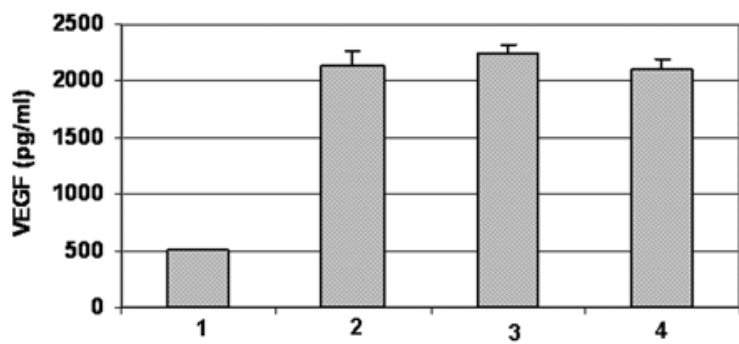

Figure 3. Sulforaphane inhibits norepinephrine-mediated increases of IL-6 but not VEGF levels in human pancreatic duct epithelial cells. (A) Human pancreatic duct epithelial cells were stimulated with 5 or $10 \mu \mathrm{M}$ of norepinephrine as well as the combination of $10 \mu \mathrm{M}$ of norepinephrine with 10 or $20 \mu \mathrm{M}$ of sulforaphane. 1 , no treatment; 2 , NE $(5 \mu \mathrm{M}) ; 3$, NE $(10 \mu \mathrm{M})$; 4, NE $(10 \mu \mathrm{M})+$ DMSO; 5, NE $(10 \mu \mathrm{M})+$ sulforaphane $(10 \mu \mathrm{M}) ; 6$, NE $(10 \mu \mathrm{M})+$ sulforaphane $(20 \mu \mathrm{M})$. IL-6 ELISA assays were determined at $24 \mathrm{~h}$ after the treatments. (B) Human pancreatic duct epithelial cells were stimulated with $10 \mu \mathrm{M}$ of norepinephrine with or without 10 or $20 \mu \mathrm{M}$ of norepinephrine. 1, no treatment; 2 , NE $(10 \mu \mathrm{M}) ; 3$, NE $(10 \mu \mathrm{M})+$ sulforaphane $(10 \mu \mathrm{M}) ; 4$, NE $(10 \mu \mathrm{M})+$ sulforaphane $(20 \mu \mathrm{M})$. VEGF ELISA assays were determined at $24 \mathrm{~h}$ after the treatments.

duct epithelial cells, we also explored its ability to inhibit IL-6 and VEGF. Interestingly, our results showed that sulforaphane reduces the increased levels of secreted IL- 6 levels in norepinephrine stimulated HPDE cells (Fig. 3A). However, 
sulforaphane does not inhibit the increased levels of secreted VEGF in norepinephrine stimulated human pancreatic duct epithelial cells (Fig. 3B). This report is the first to demonstrate that sulforaphane has an inhibitory effect on norepinephrine mediated increase of IL- 6 levels. At this time, we do not know whether the reduction of secreted IL-6 is due to the inhibition of IL-6 secretion or if inhibition is occurring at the levels of transcription or translation of IL-6.

\section{Discussion}

At present, the possible effect of chronic stress on normal human pancreatic duct cells is unclear. Our results demonstrated that stress-associated hormone, norepinephrine, can increase cell proliferation and induce increased levels of IL-6 and VEGF of immortalized human pancreatic duct epithelial cells. This is the first report that shows that norepinephrine has stimulating effects on cell proliferation and levels of IL-6 and VEGF in human pancreatic duct epithelial cells. Our data are consistent with the recent reports that norepinephrine could lead to increased expression of IL-6 mRNA and protein levels in ovarian carcinoma cells (25). These results suggest that chronic stress may serve as a cofactor to promote oncogenesis of normal or pre-neoplastic pancreatic cells.

High consumption of fruits and vegetables has been associated with a lower risk of pancreatic cancer in some case-control studies $(26,27)$. Interestingly, our results also demonstrated that the dietary agent sulforaphane but not resveratrol can inhibit norepinephrine-mediated increases in cell viability in human pancreatic duct epithelial cells. However, sulforaphane does not inhibit the cell proliferation of human pancreatic duct epithelial cells that are not stimulated by norepinephrine. Consistent with our results, Kuroiwa et al also reported the protective effects of sulforaphane but not resveratrol against initiation of $\mathrm{N}$-nitrosobis(2-oxopropyl)amine induced pancreatic carcinogenesis in hamsters (28). In addition, sulforaphane appears to have an inhibitory effect on established human pancreatic cancer cells (29). Sulforaphane also inhibits norepinephrine-mediated increases of the IL-6 levels but not VEGF levels. IL-6 is a pro-inflammatory cytokine that has been shown can stimulate the cell growth of immortalized and cancer cells (30-32), cell invasion (33) and angiogenesis $(32,34,35)$. Furthermore, we observed that norepinephrine can increase the MMP-9 levels in HPDE cells and that this induction is inhibited by sulforaphane (data not shown). This is the first report to suggest that sulforaphane, a natural compound from the Cruciferous vegetables (36), may have preventive effects on oncogenesis in HPDE cells induced by norepinephrine. Moreover, sulforaphane may have a chemopreventive effect by inhibiting norepinephrinemediated cell proliferation and IL-6 and MMP-9 levels.

In conclusion, our results suggest that chronic stress may increase cell proliferation and IL-6 and VEGF secretion of human pancreatic duct epithelial cells, at least in part, by stress-associated hormone, norepinephrine. Daily consumption of cruciferous vegetables which contain sulforaphane, especially during chronic stress, might have some preventive effects against possible norepinephrine-mediated cancer development for pancreatic carcinoma.

\section{Acknowledgements}

This work was supported in part by and an Elsa U. Pardee grant and a National Foundation for Cancer Research grant to Jiayuh Lin. We thank Dr Ming-Sound Tsao at the University of Toronto for kindly provided us the human pancreatic duct epithelial cells. We also acknowledge Drs Ronald Glaser and Eric Yang at the Ohio State University Medical Center for helpful discussions on norepinephrine and technical assistance of Brian Hutzen.

\section{References}

1. Greenlee R, Murray T, Bolden S and Wingo P: Cancer statistics, 2000. CA Cancer J Clin 50: 7-33, 2000.

2. Yeo C, Abrams R, Grochow L, Sohn T, Ord S, Hruban R, Zahurak M, Dooley W, Coleman J, Sauter P, Pitt H, Lillemoe K and Cameron J: Pancreaticoduodenectomy for pancreatic adenocarcinoma: postoperative adjuvant chemoradiation improves survival. A prospective, single-institution experience. Ann Surg 225: 621-633, 1997

3. Conlon K, Klimstra D and Brennan M: Long-term survival after curative resection for pancreatic ductal adenocarcinoma. Clinico-pathologic analysis of 5-year survivors. Ann Surg 223: 273-279, 1996.

4. Lillemoe K: Current management of pancreatic carcinoma. Ann Surg 221: 133-148, 1995.

5. Reiche EM, Nunes SO and Morimoto HK: Stress, depression, the immune system and cancer. Lancet Oncol 5: 617-625, 2004.

6. Kiecolt-Glaser JK and Glaser R: Psychoneuroimmunology and cancer: fact or fiction? Eur J Cancer 35: 1603-1607, 1999.

7. Riley V: Mouse mammary tumors: alteration of incidence as apparent function of stress. Science 189: 465-467, 1975.

8. Saul AN, Oberyszyn TM, Daugherty C, Kusewitt D, Jones S, Jewell S, Malarkey WB, Lehman A, Lemeshow S and Dhabhar FS: Chronic stress and susceptibility to skin cancer. J Natl Cancer Inst 97: 1760-1767, 2005.

9. Padgett DA and Glaser R: How stress influences the immune response. Trends Immunol 4: 444-448, 2003.

10. Glaser R and Kiecolt-Glaser JK: Stress-induced immune dysfunction: implications for health. Nat Rev Immunol 5: 243-251, 2005.

11. Levy SM, Herberman RB, Lippman M, D'Angelo T and Lee J: Immunological and psychosocial predictors of disease recurrence in patients with early-stage breast cancer. Behav Med 17: 67-75, 1991.

12. Stommel M, Given BA and Given CW: Depression and functional status as predictors of death among cancer patients. Cancer 94: 2719-2727, 2002.

13. Seidman AD, Portenoy R, Yao TJ, Lepore J, Mont EK, Kortmansky J, Onetto N, Ren L, Grechko J, Beltangady M, et al: Quality of life in phase II trials: a study of methodology and predictive value in patients with advanced breast cancer treated with paclitaxel plus granulocyte colony-stimulating factor. J Natl Cancer Inst 87: 1316-1322, 1995.

14. Coates A, Porzsolt F and Osoba D: Quality of life in oncology practice: prognostic value of EORTC QLQ-C30 scores in patients with advanced malignancy. Eur J Cancer 33: 1025-1030, 1997.

15. Ganz PA, Lee JJ and Siau J: Quality of life assessment. An independent prognostic variable for survival in lung cancer. Cancer 67: 3131-3135, 1991.

16. Lutgendorf SK, Cole S, Costanzo E, Bradley S, Coffin J, Jabbari S, Rainwater K, Ritchie JM, Yang M and Sood AK: Stress-related mediators stimulate vascular endothelial growth factor secretion by two ovarian cancer cell lines. Clin Cancer Res 9: 4514-4521, 2003.

17. Sood K, Bhatty R, Kamat AA, Landen CN, Han L, Thaker PH, Li Y, Gershenson DM, Lutgendorf S and Cole SW: Stress hormone-mediated invasion of ovarian cancer cells. Clin Cancer Res 12: 369-375, 2006.

18. Lutgendorf SK, Johnsen EL, Cooper B Anderson B, Sorosky JI, Buller RE and Sood AK: Vascular endothelial growth factor and social support in patients with ovarian carcinoma. Cancer 95: 808-815, 2002. 
19. Tammela T, Enholm B, Alitalo K and Paavonen K: The biology of vascular endothelial growth factors. Cardiovasc Res 65: 550-563, 2005.

20. Demers M, Couillard J, Belanger S and St-Pierre Y: New roles for matrix metalloproteinases in metastasis. Crit Rev Immunol 25: 493-523, 2005

21. Pomerantz J, Schreiber-Agus N, Liegeois NJ, Silverman A, Alland L, Chin L, Potes J, Chen K, Orlow I, Lee HW, CordonCardo C and De Pinho RA: The INK4A tumor suppressor gene product, p19Arf, interacts with MDM2 and neutralizes MDM2's inhibition of p53. Cell 92: 713-723, 1998.

22. Rupp H, Dhalla KS and Dhalla NS: Mechanisms of cardiac cell damage due to catecholamines: significance of drugs regulating central sympathetic outflow. J Cardiovasc Pharmacol 24 (Suppl. 1): S16-S24, 1994.

23. Schmidt $\mathrm{C}$ and Kraft K: Beta-endorphin and catecholamine concentrations during chronic and acute stress in intensive care patients. Eur J Med Res 1: 528-532, 1996.

24. Wu W, Yamaura T, Murakami K, Ogasawara M, Hayashi K, Murata $\mathbf{J}$ and Saiki I: Involvement of TNF-alpha in enhancement of invasion and metastasis of colon 26-L5 carcinoma cells in mice by social isolation stress. Oncol Res 11: 461-469, 1999.

25. Nilsson M, Armaiz-Pena G, Takahashi R, Lin Y, Trevino J, Li Y, Jennings N, Arevalo J, Lutgendorf S, Gallick G, Sanguino A, Lopez-Berestein G, Cole S and Sood A: Stress hormones regulate IL- 6 expression by human ovarian carcinoma cells through a SRC-dependent mechanism. J Biol Chem 282: 29919-29926, 2007.

26. Olsen G, Mandel J, Gibson R, Wattenberg L and Schuman L: Nutrients and pancreatic cancer: a population-based case-control study. Cancer Causes Control 2: 291-297, 1991.

27. Nkondjock A, Krewski D, Johnson K, Ghadirian P and Group CCRER: Dietary patterns and risk of pancreatic cancer. Int J Cancer 114: 817-823, 2005.

28. Kuroiwa Y, Nishikawa A, Kitamura Y, Kanki K, Ishii Y, Umemura $\mathrm{T}$ and Hirose M: Protective effects of benzyl isothiocyanate and sulforaphane but not resveratrol against initiation of pancreatic carcinogenesis in hamsters. Cancer Lett 241: 275-280, 2006.
29. Pham NA, Jacobberger JW, Schimmer AD, Cao P, Gronda M and Hedley DW: The dietary isothiocyanate sulforaphane targets pathways of apoptosis, cell cycle arrest and oxidative stress in human pancreatic cancer cells and inhibits tumor growth in severe combined immunodeficient mice. Mol Cancer Ther 3: 1239-1248, 2004.

30. Iglesias M, Plowman G and Woodworth C: Interleukin-6 and interleukin-6 soluble receptor regulate proliferation of normal, human papillomavirus-immortalized and carcinoma-derived cervical cells in vitro. Am J Pathol 146: 944-952, 1995.

31. Chang K, Tsai C, Chiou Y, Chiu C, Jeng K and Huang C: IL-6 induces neuroendocrine dedifferentiation and cell proliferation in non-small cell lung cancer cells. Am J Physiol Lung Cell Mol Physiol 289: L446-L553, 2005.

32. Wei L, Kuo M, Chen C, Chou C, Lai K, Lee C and Hsieh C: Interleukin- 6 promotes cervical tumor growth by VEGFdependent angiogenesis via a STAT3 pathway. Oncogene 22: $1517-1527,2003$.

33. Lin M, Lin B, Chang C, Chu C, Su H, Chen S, Jeng Y and Kuo M: IL-6 induces AGS gastric cancer cell invasion via activation of the c-Src/RhoA/ROCK signaling pathway. Int J Cancer 120: 2600-2608, 2007.

34. Jee S, Chu C, Chiu H, Huang Y, Tsai W, Liao Y and Kuo M: Interleukin-6 induced basic fibroblast growth factor-dependent angiogenesis in basal cell carcinoma cell line via JAK/STAT3 and PI3-kinase/Akt pathways. J Invest Dermatol 123: 1169-1175, 2004.

35. Nilsson M, Langley R and Fidler I: Interleukin-6, secreted by human ovarian carcinoma cells, is a potent proangiogenic cytokine. Cancer Res 65: 10794-10800, 2005.

36. Aggarwal B and Shishodia S: Molecular targets of dietary agents for prevention and therapy of cancer. Biochem Pharmacol 71: 1397-1421, 2006. 